\title{
6
}

\section{Pacific policy pathways: Young women online and offline}

\author{
Tait Brimacombe \\ La Trobe University
}

In her book The Network Inside Out, Annelise Riles (2001) examined the national, regional and international processes that took place between 1994 and 1996 in the lead up to the Fourth World Conference on Women and the production of the Pacific Platform for Action. Nearly 20 years later, the progress made against these gender equality commitments was both celebrated and critiqued at the 12th Triennial Conference of Pacific Women in Rarotonga, 2013. While this event provided an opportunity to reflect on the progress made and future challenges to the promotion of gender equality, it also offered an opportunity to examine current practices of coordination and networking for Pacific women, particularly as a younger generation of emerging women leaders attempted to forge pathways towards engagement in policy spaces.

Scholars such as Naila Kabeer $(2011,2012)$ and Srilatha Batliwala (2008) have recognised the power of association and collective action for women's movements in their pursuit of transformational change, as well as the more intrinsic impact that this relationship-building and solidarity can have on participants. In this chapter, I explore these themes through an ethnographic case study of the Pacific Young Women's Leadership Alliance (PYWLA), their participation at the 12th Triennial Conference in 2013 and their engagement with both online and offline (face-to-face) communication platforms. It is suggested that recent technological 
advances throughout the Pacific region have helped generate new regional, international and indeed virtual avenues for participation and dialogueincluding through increasingly popular social media platforms. Using the example of the PYWLA, I analyse some of the preliminary ways in which these emerging technologies are being utilised alongside broader, more conventional processes of face-to-face collective action and policy engagement. This chapter is based on data collected as part of a broader, multisited $\mathrm{PhD}$ research project over the course of 2013.

\section{Coalitions and collective action}

Pacific women face barriers to participation in dialogue and decision-making because of the patriarchal nature of many decision-making institutions and structures, and gendered assumptions about the nature of leadership as an inherently male trait (McLeod 2015; Soaki, this volume). Recent research in the Pacific has tended to concentrate on women's participation in the formal political realm (Corbett and Liki 2015; Donald, Strachan and Tales. 2002; Douglas 2002b; McLeod 2002; Spark and Corbett 2016), with less attention paid to women's participation and leadership in civil society and through the work of coalitions, despite the importance of this domain for challenging and transforming gendered power structures and relations and addressing the obstacles that inhibit women's participation and leadership. Participation in civil society and coalitions provides Pacific women with opportunities to influence the delivery of services and lobby governments regarding issues of concern to them (McLeod 2015).

Civil society organisations and coalitions in the Pacific have given women an opportunity to 'challenge the status quo' in quieter and subtler ways, acting as a vehicle for the pursuit of social and political change and a platform from which to lobby for legislative and policy change (DicksonWaiko 2003; George 2014; McLeod 2015; Monson 2013; Paina 2000). In particular, faith-based organisations have historically offered women a platform for leadership training and skills, and a forum through which to exert influence (Douglas 2002a; McDougall 2003; Pollard 2003). As such, faith-based organisations have become a vehicle for the development of activist practice, raising the profile of issues warranting legislative and policy attention (Dickson-Waiko 2003).

From a policy perspective, the Pacific region has a strong framework dedicated to the promotion of gender equality—for example, the 2012 Pacific Leaders Gender Equality Declaration to advance progress towards 
the implementation of Convention on the Elimination of All Forms of Discrimination against Women (CEDAW) commitments, and the Revised Pacific Platform for Action. Women's collective action has been instrumental in the development of these policy platforms, with women's coalitions linking their work to global discourses and key policy agendas to highlight specific issues of concern (George 2009, 2012).

Pacific women identified a particular need to make their presence felt on a regional and international stage in the lead up to the UN Fourth World Conference on Women in Beijing in 1995 (George 2009, 2012; Riles 2001). As part of the pre-conference process for the region, the Beneath Paradise Project (funded by International Women's Development Agency (IWDA) and AusAID) brought together activists from throughout the Pacific region under the catch cry 'See us, hear us, Beijing' with a view to documenting the statements and stories of Pacific women:

Over the three-year period in the lead-up to the Beijing Conference, this project, involved women from twenty-one NGOs in eight Pacific Island countries. They documented women's life stories, strengths, achievements, needs and struggles through a rich collection of stories, photographs, soundscapes, slideshows, testimonials and poetry (IWDA 2015: 18).

Reflecting on their involvement in these events on the occasion of the twentieth anniversary of the conference and the adoption of the Beijing Declaration and Platform for Action, IWDA emphasised the solidarity and lasting bonds formed in Beijing: 'International meetings provide opportunities for women's organisations to prove their relevance and raise funds, to strengthen networks and create new partnerships, networks and opportunities' (2015: 19).

Scholars such as Kabeer $(2011,2012)$ have recognised the potentially transformative value of collective learning processes and social relationships developed when women coalesce around a common agenda. Batliwala (2008) suggests that changes in policy and structural norms, such as through CEDAW or the Beijing Platform for Action, could not have been achieved without the collective power exerted through organised lobbying and mobilisation of women's organisations and activists. For Kabeer (2012), this type of collective action enables the formation of safe spaces for women to discuss issues of common concern and facilitate processes of shared reflection. The solidarity gained through building relationships on shared experiences can be instrumental to achieving strategic gains across local, national and international arenas (Kabeer 2011, 2012; Kabeer and Huq 
2010). In addition to the instrumental value of such collective action, and the inherent value of coalitions as power in numbers, there are also subtler, yet equally transformative dynamics at play. This is best highlighted by Kabeer and Huq in their discussion of a women's organisation in Bangladesh:

The bonds of friendship and solidarity between group members had been forged and strengthened through many years of dealing with adversity together. It was the power of these social relationships that they drew on in confronting relationships of power within their community (2010: 86).

As this quote demonstrates, the formation of strong relationships based on solidarity among groups of women with shared experiences can be crucial to the generation of momentum for social change.

Ceridwen Spark $(2010,2014)$ has described how this notion of solidarity and support is manifest within groups of young, educated Melanesian women. This is particularly relevant given the double disadvantage faced by young women in the Pacific by virtue of both their age and genderincreasingly marginalised from dialogue and decision-making processes that are either male-dominated or restricted to older generations of women leaders. Furthermore, initiatives aimed at encouraging youth participation in the Pacific 'are still dominated by young men while young women continue to face considerable barriers to inclusion' (World YWCA 2011: 13). Even when given spaces to participate, young women face barriers due to cultural and traditional expectations of hierarchy and respect, and a devaluing of their voices by virtue of both their age and gender. Referring to her research with young women leaders in Vanuatu, Spark notes:

Ideally, young women would derive strength and support from earlier generations of women who have grappled with similar if not equivalent challenges and who might provide a source of advice and advocacy. Unfortunately this is not the case in Vanuatu. Instead, the young women spoke about the collective experience of being dismissed and denigrated by older women ... in meetings, emails and in local media ... too young to know anything and lacking sufficient life experience to make decisions. The young women were silenced in meetings, or, when they did speak out, berated for being disrespectful (2014: 1-2).

Transgenerational barriers such as these are common throughout the Pacific region, with a lack of formal mentoring avenues or opportunities for information exchange and knowledge sharing. That being said, some examples of best practice are evident through a few initiatives such as the Young Women's Parliamentary Group in Solomon Islands, the Fiji Young 
Women's Forum, and the Fiji Women's Rights Movement (FWRM) Emerging Leaders Forum and associated alumni. Despite these initiatives, the collective capacity and potential of young women in the Pacific is not widely understood, with a need for innovative mechanisms to promote meaningful and active participation of young women in dialogue and decision-making.

For Kabeer (2012), collective action and communities of practice, or coalitions, enable women to acquire new knowledge and information, forge new relationships with each other and carve pathways for future engagement. As the above literature demonstrates, this is an ever-present need felt by young women in the Pacific. In this chapter, I draw on the ethnographic case study of the PYWLA to highlight one process by which young women have forged a pathway for themselves into the regional policy arena; and how the Pacific's recent technological revolution has enabled the formation of online networking and dialogue processes alongside more conventional face-to-face participation formats.

\section{The Pacific 'technological revolution'}

Until recently, the Pacific region had been relatively slow to respond to the global increase in the uptake of new information communication technologies (ICTs), largely as a result of geographic isolation, small population size, high operating costs and the presence of telecommunications monopolies (PiPP 2012). However, since 2003 the Pacific telecommunications sector has undergone significant reform and deregulation, resulting in lower access costs and increased uptake of ICTs (Cave 2012). In the past two years, infrastructure advances have seen the expansion of the Southern Cross Fibre Optic Cable through Fiji to Tonga and Vanuatu; ${ }^{1}$ and the improvement of satellite networks in the Cook Islands, Palau and Federated States of Micronesia (FSM) through partnerships with $\mathrm{O} 3 \mathrm{~b}^{2}$

\footnotetext{
1 The Southern Cross Fibre Optic Cable is a trans-Pacific network of telecommunication cables connecting Australia and New Zealand with the USA, with a landing point in Fiji. As part of the Pacific Regional Connectivity Project (funded through the World Bank and the Asian Development Bank) this connection was extended to other Pacific Island countries over the course of 2013 and 2014.

2 O3b Networks Ltd stands to represent the 'other three billion' people who are not connected to fibre optic internet. O3b partner with companies such as Google, HSBC and SES satellites to provide bandwidth via satellite upgrade. Although a relative newcomer to the Pacific, O3b claims that their satellites can offer network speeds comparable with fibre optic.
} 
This 'technological revolution' is being sustained and accelerated by the region's large youth population, with evidence suggesting that Pacific youth are the fastest adopters of new technology (Cave 2012). 'In urban, and increasingly in rural settings Pacific Islanders are using new digital tools to communicate, form online networks and coordinate' (Cave 2012: 1). In 2012, it was estimated that approximately 60 per cent of Pacific Islanders had access to mobile phones (Cave 2012). Although there is a shortage of reliable, more recent statistics, anecdotal evidence suggests that in some Pacific Island countries, mobile phones are at near saturation rate. This widespread access to and use of mobile phones, alongside aforementioned advances in internet infrastructure, opens up the potential for widespread mobile internet access and use.

This, in turn, has facilitated a rise in social media throughout the region. In late 2012, it was estimated that the Pacific had approximately 700,000 Facebook users, with 150,000 of those joining over the course of 2012 (Cave 2012: 7). Five Pacific Island countries were ranked in Facebook's top 20 growth market from April to September 2012 (when considered as a percentage of total population), with the majority of this growth occurring within a 16-34 age bracket (Cave 2012: 7). While more recent statistics for the region are unavailable, it is reasonable to infer that such a high uptake rate in 2012, combined with the aforementioned infrastructure improvements in countries such as Tonga and Vanuatu in 2013 and 2014, would see an acceleration in the number of Facebook users in the region. The unprecedented increase in social media use throughout the Pacific region makes it an under-researched area, with the majority of the limited literature to date focusing on the use of social media and new ICTs for the promotion of democracy, increasing government transparency and accountability and improving electoral processes (Finau et al. 2014; Haley and Zubrinich 2015; Logan 2012); kinship, gender and mobile phone use (Andersen 2013; Lipset 2013; Taylor 2016); and the potential that such mobile technologies bring for increasing the flow of information, finances and transactions between Pacific Islanders at home and in the diaspora community abroad (Lee 2006; Nishitani 2014).

Facebook and other social media sites have enabled the creation of new online communities, facilitated discussion on a host of socio-political topics, and provided Pacific Islanders with new opportunities to engage in low-cost dialogue at a domestic, regional and international level. Vanuatu's 'Yumi Toktok Stret' (over 28,000 members), PNG's Sharp Talk (over 26,000 members), 'Forum Solomon Islands International' (FSII) 
(over 17,000 members), and 'Fiji's Letters to the Editor Uncensored' (LTEU) (over 17,000 members) all offer examples of the potential of such online forums for promoting debate and dialogue on key issues of policy relevance, as well as broader socio-political topics. Glen Finau et al. (2014) have explored these platforms as models of e-democracy. Vanuatu's 'Yumi Toktok Stret' has been utilised by citizens and politicians alike, facilitating debate between government representatives, the opposition party and constituents, while acting as a source of information and discussion for mainstream media. As explored in previous work, 'Yumi Toktok Stret' has also been used as a forum for debate and dialogue around gender equality, allowing users to mediate competing narratives concerning gender equality, kastom, Christianity and human rights (Brimacombe 2016). Similarly, in Solomon Islands' FSII, a popular Facebook group with a mandate of exposing corruption and promoting transparency, is now registered as a civil society organisation in the wake of increasing interest and growth (Finau et al. 2014). The popularity of such discussion groups is fuelled, in part, by increasing youth engagement with social media, particularly in the wake of comparatively few opportunities for participation in more traditional, conventional discussion forums. As Helen Lee notes in her exploration of Tongan discussions forums: 'Young people were given a voice through $K B$ [Kava Bowl] and other sites in a way they had not experienced within their own families and communities' (2006: 164).

This increase in social media use has resulted in the emergence of a Pacific 'digital generation' of activists (Cave 2012: 3). Activists are increasingly recognising the potential of the internet and social media as a force for social change and a vehicle for the inclusion of marginalised groups. While these online forms of activists are often dismissed as lacking authentic participation, and labelled as 'slacktivism' (Christensen 2011), such a conceptualisation fails to recognise the potential for online platforms to mobilise movements and collective action, forge new social relations and solidify networks (Gerbaudo 2012; Kahn and Kellner 2004). As Paul Gerbaudo notes, 'Social media have become emotional conduits for reconstructing a sense of togetherness among a spatially dispersed constituency' (2012: 159).

However, these new ICTs are not without their limitations-geographic constraints (with a strong urban bias among Pacific internet users), infrastructure and equipment limitations, access barriers as a result of limited education and literacy, and running costs. In addition, with 
increased internet access comes community concerns regarding the accessing of pornographic content, ${ }^{3}$ cybercrime, fraud (Cox 2014), and cyberbullying and harassment. ${ }^{4}$ Online discussion forums and social media have the potential to act as platforms for both progressive and regressive sentiments simultaneously. As noted by Jo Sutton and Scarlet Pollock in their discussion of online activism:

The speed, immediacy, transparency, global reach, effectiveness, increased means for communication, and potential for civic participation through multi-way communication are only part of the picture. They need to be weighed against the difficulties associated with communication technology—-the workload increase, health hazards, costs, techno-cultural shock ... and the need to develop new ways of working together that take time and effort to learn (2000: 701).

\section{Pacific Young Women's Leadership Alliance}

The PYWLA emerged as part of a 2011 World YWCA process of consultation and workshops in the Pacific, culminating in the development of the YWCA Pacific Regional Young Women's Leadership Strategy (2011-2014). This strategy highlighted the need for a network of organisations in the Pacific to further advocate on issues of young women's leadership, with the PYWLA emerging as a way of continuing such work. ${ }^{5}$ PYWLA's goal is to provide a platform for the sharing of information and resources, as well as offering a united voice to hold governments and donors accountable to Pacific young women. In doing so, the PYWLA aims to provide a platform for Pacific young women to engage with and influence policy.

3 In February 2015, it was announced on Radio Australia that PNG had the greatest percentage of internet searches for the words 'porn' and 'pornography' via the search engine Google, a revelation that, although widely criticised, ignited public debate about the role of the internet and social media in Pacific societies.

4 Roshika Deo, a candidate in Fiji's 2014 election, whose 'Be the Change' campaign relied heavily on social media platforms, has spoken publicly on the negative comments and threats that were posted on her Facebook page. She was ultimately forced to seek police intervention to combat the cyber-attacks and harassment.

5 Nicole George $(2009,2012)$ has explored how the local and transnational nature of Fiji's YWCA has historically enabled an entry point for women's organising into a national realm, as part of political debates, as well as playing a central role in regional conferences as a strong voice for the Pacific on an international stage. The PYWLA can be seen as building upon this history. 
The model of the PYWLA is loosely based on a constellation model of collaborative social change developed for the Canadian Partnership for Children's Health and Environment (CPCHE), seeking to bring together groups from multiple sectors to work towards a joint outcome in situations where no one group, on its own, has the resources or mandate. This partnership model places emphasis on the role of small action teams, joined together as part of an overall partnership, with a fluid framework of leadership sharing (Surman and Surman 2008). This rotating system of decision-making, authority and resources through constellation partners places emphasis on the natural energy flows present in a group dynamic, and enables flexibility to respond to opportunistic endeavours rather than requiring rigidity in strategic planning: 'constellations are "loosely coupled" together to create a rough and chaotic whole' (ibid.: 27).

Consistent with this model, the PYWLA represents an alliance between a host of local, national, regional and international organisations and networks including International Planned Parenthood Federation (IPPF), IWDA, Commonwealth Youth Programme, Pacific Youth Council, Secretariat of the Pacific Community (SPC), YWCA, FWRM, FemLINKpacific, United Nations Population Fund (UNFPA), UNICEF and UN Women, as well as smaller, grassroots organisations and youth councils operating at a local level. In accordance with the constellation model, there is recognition of the existing commitments and networks of alliance members, with a view to using the PYWLA to further amplify the voices of young women and expand existing connections. The alliance selected FWRM as the secretariat-responsible for the coordination and accountability of constellation members.

\section{Online}

One of the first initiatives of the PYWLA was to convene a Pacific Young Women's Dialogue. The first phase of this dialogue took place online, through a closed social media group. Between June and October 2013, over 100 Pacific young women participated in Facebook conversations as part of the PYWLA Online Dialogue Series. Owing to the sensitive and personal nature of these online discussions, and the carefully curated sense of privacy afforded by the closed nature of the Facebook discussion group, the following section will draw upon data that has been made publicly available in the subsequent reporting on these discussions. 
The aim for these dialogues was to provide young women with an opportunity to express their opinions and network with each other online, with a view to using the information obtained during these dialogues as part of wider discussions with Pacific governments and the donor community to lobby for support for young women's leadership. Discussion was loosely structured around the World YWCA's (2011) Pacific Young Women's Leadership Strategy, which articulated a desire for young women to feel safe, respected, included, connected and skilled. ${ }^{6}$ These five broad themes were leveraged by the PYWLA, with seven specific dialogue discussions focusing on: 1) transformational leadership; 2) sexual and reproductive health rights; 3) participation; 4) bodily security; 5) peer-to-peer learning; 6) women, peace and security; and 7) gender, economic and ecological justice rights. During the discussions, specific questions were posed to online participants, with each discussion being moderated by two people, chosen from the constellation of PYWLA member organisations according to their thematic expertise.

The online discussion began by posing the questions: What does transformation leadership mean to you? What obstacles do young women face, and how can more young women leaders be encouraged? Through these discussions, young women participants identified the characteristics of transformational leaders-particularly inclusivity and involvement in collective decision-making, public visibility, the promotion of social change, and reflection and learning (PYWLA 2013). Participants in the online dialogues felt as though culture and tradition, particularly rigid expectations imposed on young women by virtue of their age and gender, limited their access to resources, information and educational opportunities (PYWLA 2013). These limitations were compounded by a lack of support from older generations of women leaders and limited opportunities for mentoring or information sharing between generations. As a result of this, peer-to-peer learning spaces (such as the online dialogues themselves) emerged as key platforms to promote honest dialogue and reflection, and encourage conversation among peers on potentially sensitive and taboo topics.

6 Safe from violence, conflict, disasters and climate change; respected in terms of sexual and reproductive health rights, bodily security, self-esteem and confidence; included as minority groups with recognition of the intersectional discrimination faced by young women with diverse sexual orientations and gender identities and women with disabilities; included in leadership and decisionmaking processes; connected through a variety of media and communication channels and social movements; and skilled through access to quality education, employment and training. 
A strong theme emerging from the online dialogue series was the need for comprehensive sexual health education, and greater recognition of the sexual and reproductive health rights of young women. Participants expressed concern over the high rates of teenage and unplanned pregnancy in the Pacific, with 'blame' for these pregnancies often placed on young women (PYWLA 2013). Participants felt that existing measures to improve access to family planning information and services had not been sufficiently inclusive, with a need for participatory dialogue to break down cultural taboos around sexual health issues (PYWLA 2013). Participants who had engaged with the sexual health curriculum in schools lamented the poor quality and format with which it was delivered, and called for a greater sensitisation of education providers, and greater inclusion of comprehensive sex education, including appropriate content targeted at primary school children (PYWLA 2013).

Despite the diverse sociocultural backgrounds of participants contributing to the online discussion, and contextual differences in thematic issues, some clear commonality emerged between participant experiences. At the end of the online dialogue series, these common themes were summarised into a PYWLA Online Dialogue Issues Series publication, designed as a lobby and advocacy tool for use in the work of the alliance.

\section{Offline}

The second phase of the Pacific Young Women's Dialogue took place offline, enabling face-to-face participant interaction. This offline dialogue was designed to coincide with the 12th Triennial Conference of Pacific Women in Rarotonga, 21-24 October 2013 (hereafter the Conference). As such, the dialogue was designed to support the preparation and engagement of young women leaders in the Conference proceedings and associated events by building the practical skills and networks of young women participants, as well as furthering the advocacy agenda through which to lobby decision-makers. Participants for the offline dialogue were selected with a view to promoting inclusivity of marginalised groups, ensuring representation from a variety of Pacific Island countries, and with a preference for participants who had actively taken part in the online dialogues. 
From 18-20 October, 26 participants from throughout the Pacific region, ${ }^{7}$ came together in Rarotonga for the pre-conference PYWLA dialogue. In addition, nine facilitators were present, selected from PYWLA's member organisations. ${ }^{8}$ Over the course of the three-day participatory dialogue, participants developed advocacy skills, identified potential resources and mobilisation points, and highlighted pathways into decision-making roles.

One of the main aims of the PYWLA dialogue was to bring together a critical mass of young women leaders to strengthen their networks and leadership and advocacy skills. As part of this, participants were introduced to the processes, language and terminology of regional events such as the Triennial Conference and familiarised with the 'rules of the game'what they would need to know in order to meaningfully engage in the Conference. In support of this, PYWLA participants were divided into small groups - known as 'hubs' - to ensure participants were adequately prepared to take full advantage of all advocacy avenues at the Conference, and to provide adequate representation of the PYWLA collective through all conference plenaries, panels and side events. One 'hub' was responsible for the drafting of the PYWLA outcome document and opening statement, as well as acting as a lobbying conduit facilitating interactions between PYWLA participants and relevant delegates and ministries; a second 'hub' was responsible for creative endeavours-developing artwork and interpretative performances for display at the Conference; another 'hub' was responsible for media outputs—curating press releases and managing social media accounts; with a final 'hub' responsible for managing the PYWLA booth at the Conference-ensuring resources and materials were available for dissemination. This 'hub' approach, with leadership responsibilities horizontally dispersed among participants, ensured the collective PYWLA 'voice' was heard across multiple channels during the Conference itself and associated media coverage. As one participant reflected:

7 Participants included representatives from Vanuatu, Tuvalu, Cook Islands, Nauru, Marshall Islands, Kiribati, PNG, Solomon Islands, Samoa, Tonga, Niue and Fiji.

8 Facilitators were from Development Alternatives with Women for a New Era (DAWN), FemLINKpacific, FWRM, SPC, UN Women, UNFPA, and Punanga Tauturu Inc. (Cook Islands Women's Counselling Centre), who were the host organisation. 
What made a huge difference [at The Triennial] was the three-day dialogue organized by the PYWLA ... This dialogue gave us the opportunity to discuss our key issues, share with each other our recommendations ... friendships were formed, which would definitely last a lifetime for many ... The fact we knew we had each other to turn to during The Triennial, especially for support, sharing of ideas and techniques on lobbying and advocacy, helped us a lot ... The young women spoke as one voice (personal correspondence, PYWLA participant from Fiji, 24 October 2013).

The first day of the PYWLA dialogue included a mapping of the regional and global gender processes and key policy commitments, with participants drawing links between work that was carried out 'on the ground' and work being carried out as part of these broader regional and international processes. Participants-as both individuals and in small groups-were encouraged to brainstorm and share what issues they felt were most important to themselves and other young women in their country. These brainstorming endeavours included the mapping of a 'life tapestry' to identify inequality across a woman's lifetime, and the development of a 'problem tree' useful for discussing the underlying structural inequality behind key policy objectives. Over the course of the PYWLA dialogue, participants were encouraged to prioritise these issues, identifying which priority issues could capitalise on existing momentum and link in with particular conference focus areas. These issues were clustered under key PYWLA themes—safe, respected, included, connected and skilled.

Over the course of the three-day dialogue, the young women's priorities were discussed and refined, until they were eventually combined into a cohesive vision and statement for Pacific young women, one that was the subject of mutual agreement and capable of clear articulation during conference proceedings. This outcome document, entitled 'The Future We Want', called upon leaders in the spirit of partnership to respond to young women's needs and concerns. The document also outlined the PYWLA's five strategic recommendations, developed throughout both the online and offline dialogue processes: 1) eliminating sexual and gender based violence; 2) ensuring sexual and reproductive health rights; 3) eliminating all forms of discrimination against persons with disabilities; 4) promoting full and decent employment and economic empowerment for young women; and 5) ensuring full participation of young women at all levels of decision-making. The document concluded by proclaiming 'Pacific Young Women want to be safe, respected, included, connected and skilled'. 
The PYWLA dialogue also saw participants engaged in a stakeholder power analysis-a process designed to recognise the different interests and spheres of influence associated with key regional and international stakeholders, as well as identify potential entry points for collaboration on focus issues. For many of the PYWLA participants, the Conference represented a valuable entry point in itself, offering an opportunity to network with representatives from the Women's Machineries in their own country, key international actors such as the UN offices and AusAID, and local and international media outlets. For some PYWLA participants, such networking was often the first opportunity they had been given to meet with representatives from their own national delegation. The potential impact of such connections was not lost on participants, as one participant from Vanuatu reflected:

I have really used this conference as a way to engage with the delegation from the Vanuatu Department of Women's Affairs. The Director of the Department came up to me wanting to talk about my work, so this has been a great opportunity to network with delegates from my own country (interview, PYWLA participant from Vanuatu, 22 October 2013, Rarotonga).

During the PYWLA dialogue, participants identified strategic entry points for the communication of their young women's agenda at the Conference. As part of this process, space was negotiated for one PYWLA representative to be included in the Conference opening proceedings, delivering a statement alongside the Cook Islands Minister for Women and the Deputy Director General of SPC. Ina Vakaafi, a PYWLA participant from Niue, was chosen. Her statement, drawing heavily on the PYWLA dialogue outcome document, highlighted the value of including Pacific young women in dialogue and decision-making processes, noting that 'no meaningful democracy or sustainable development can occur without involving young women', calling on national governments to include young women's issues on their national agenda.

Some PYWLA participants were able to negotiate presentation spaces in official conference panels - with one participant from the Marshall Islands giving a short presentation on the gendered dimensions of climate change and its impact on youth; and another participant from Fiji presenting on sexual and reproductive health rights and calling for the need for age-appropriate comprehensive sex education. For other PYWLA participants, not included on the Conference agenda as official presenters, there was a need to ensure they took advantage of opportunities for active 
participation as observers and during question time. During presentations on women's access to health services, one PYWLA participant from Fiji approached the chair and requested space to make a brief statement from the floor-delivering a powerful statement about her experience as a survivor of child sexual abuse. She reflected on the insistence of taboos on the discussion of sex as part of 'Pacific culture' and discussed the resulting lack of sexual understanding she held as a child and young adult. She concluded her presentation by imploring delegates to prioritise comprehensive sex education within the school curriculum.

In addition to participating in formal conference proceedings and plenary discussions, the PYWLA also hosted a side event in the early evening of the Conference's second day. This event took place in the main auditorium and was well attended by representatives from official delegations. The side event began with a creative expression of the key issues facing Pacific young women, including the performance of an illustrative dance focusing on the themes safe, respected, included, connected and skilled. Participants, who had been rehearsing for most of the week, broke into small groups to perform short tableaus, each representing one of the five themes, incorporating sign language articulations for their chosen theme (in recognition of the incorporation of a hearing-impaired woman in the PYWLA delegation). This creative performance was followed by a more formal presentation outlining the purpose of the PYWLA and the hopes that Pacific young women held for the future, concluding with the powerful statement 'our voices need to be heard and urgent action taken ... don't forget us, include us'. The presentations closed to a standing ovation from the audience, with the PYWLA side event referenced on multiple occasions during formal conference proceedings and recalled as a memorable highlight for many official delegates in attendance.

Recognition of the value of creative expression was evident throughout the PYWLA dialogue processes, as the following excerpt from my field notes demonstrates:

When I arrived at the second day of the PYWLA Dialogue, there were five large pieces of white canvas spread out on the ground alongside paints and paintbrushes. At the top of these pieces of canvas were written the terms-Safe, Respected, Included, Connected, Skilled. Over the course of the dialogue participants painted images and words under each of these headings to show how they wanted to be treated and what their hopes and aspirations were for the future (19 October 2013, Rarotonga). 
These pieces of canvas were subsequently displayed in the foyer of the Conference auditorium as a powerful visual statement and strategic talking point. This eye-catching artwork was strategically included in the background of many conference photographs and TV interviews.

Throughout the PYWLA dialogue and conference events, efforts were made to include those participants who were not able to attend in person. The Facebook platform, which had played host to the online dialogue series, was utilised once more to ensure that PYWLA members not in attendance were able to have their voices heard as part of the discussions. Updates from the dialogue and conference were shared on the PYWLA Facebook page (both the publicly visible page, and the closed group), and were subsequently shared by participants on their personal pages and the social media pages of their own organisations. During the preconference dialogue, these platforms were used to encourage comments and questions from online participants, which were then fed into realtime offline discussions, with Facebook comments and posts attempting to replicate the face-to-face dialogue and discussion topics.

Reflecting on her involvement in the International Forum of the Association of Women's Rights in Development, Kabeer (2012) noted the uplifting and transformational aspects of women's collective action, highlighting the diversity of issues discussed, and efforts made to promote inclusion and respect for difference. Despite this diversity and difference, that 'they can nevertheless come together and gain strength from gatherings of this kind is testimony to the power of a shared and inclusive politics' (Kabeer 2012: 1). These sentiments are reinforced by the PYWLA experience. As one participant from Fiji noted whilst reflecting on her participation in the events:

Having the Pacific Young Women's Leadership Alliance forum prior to The Triennial is a groundbreaking moment for a lot of young women. It is the first time we have had this many young women present for a meeting such as this ... To be in the midst of amazing young women and to hear what they have been doing in their communities and within their networks ... is very encouraging and empowering (personal correspondence, PYWLA from Fiji, 24 October 2013).

Throughout conference proceedings, PYWLA representatives were able to present a united front by virtue of the strong relationships and bonds that had been fostered through both the online and offline dialogues. These dialogues enabled a safe space for participants to share their experiences, 
often at a very personal and emotional level. During the three-day preConference PYWLA program, space was intentionally set aside at the end of each day for honest reflection as part of a 'sharing circle', with participants encouraged to lodge regular 'emotional weather reports' to ensure that they were feeling safe and supported during the emotionally intense discussions. During the PYWLA workshop, participants were asked to reflect and share (either through text, artwork, poetry or whichever form they were most comfortable with) their thoughts on situations in which they had felt powerless in contrast to situations in which they had felt powerful. As part of these processes, many PYWLA participants shared painful personal stories, reflecting on the powerlessness they felt during times of violence, conflict, loss and illness. At the end of the emotional discussions, participants expressed gratitude at the fostering of a safe space for the sharing of these stories, many of which were being expressed for the first time, and the sense of unburdening felt by the shedding of emotional baggage. Participants took solidarity in the fact that they were no longer facing these issues on their own, but were now sharing them with their 'Pacific sisters'. Reflecting at the conclusion of the conference, one PYWLA representative noted:

Many of the young women were able to articulate their key issues, but were also able to connect with other young women within the Pacific region and connected at a very personal level. During the three days of the Triennial, many of the young women remained connected with each other, and at the same time lobbied for their key issues ... The Triennial experience was not only about advocating and lobbying for our issues, but was also about bonding and building new friendships. It was about learning best practices from each other and finding ways of staying connected.

\section{Conclusion}

Now, more than two years after the Triennial Conference the question needs to be asked: What now? This is a question that is largely beyond the scope of this chapter to answer. However, it is clear that the role of the PYWLA has changed in the absence of a key regional event around which to mobilise. The number of active alliance organisations has reduced to largely Suva-based groups, with FWRM retaining their role as secretariat. PYWLA updates indicate that the majority of recent events have been limited to Suva-based participants due to logistical and financial 
limitations, and while regional participants are still encouraged to utilise the Facebook forum, there has been limited structured or meaningful engagement. This suggests that perhaps the PYWLA is losing its broader regional focus. However, as Kabeer (2011) notes, the building of group solidarity is rarely a flawless process, but can nevertheless be an important source of collective strength despite setbacks.

The constellation model, on which the PYWLA is loosely based, emphasises the importance of variations in the natural flow of energy, with the potential for partners to become dormant during periods of low energy or limited opportunities yet reignite to work on a particular issue or activity (Surman and Surman 2008). While it would appear that existing 'natural energy flows' associated with the PYWLA reside in Suva, unsurprisingly given its role as a regional administrative hub, the model would suggest that this does not necessarily result in the permanent narrowing of the network. Perhaps the true test for the PYWLA will come in their ability to reinvigorate in the context of key regional and international events and reactivate dormant alliance partners.

It is unclear what role, if any, the PYWLA will play for Pacific young women in future years, and it is beyond the scope of this chapter to speculate on the long-term impacts of participation in the alliance. Indeed:

the changes brought about by these group activities do not follow some linear trajectory whereby women go from a state of powerlessness to one of empowerment. What emerges instead is a variety of different processes and critical moments-in the lives of individual women and of their groups-that interact and spark off on each other until they solidify into a coherent movement for change (Kabeer 2012: 3).

Emerging women leaders in the Pacific are forging pathways to policy engagement in a world mediated by new technological opportunities. This examination of young women's online and offline dialogues illustrates some of the ways that young women are able to articulate their concerns and participate in processes that will transform their lives.

\section{References}

Andersen, Barbara. 2013. 'Tricks, lies and mobile phones: "Phone friend" stories in Papua New Guinea'. Culture, Theory and Critique 54(3): 318-34. doi.org/10.1080/14735784.2013.811886. 
Batliwala, Srilatha. 2008. Changing Their World: Concepts and Practices of Women's Movements. Toronto: Association for Women's Rights in Development (AWID).

Brimacombe, Tait. 2016. 'Trending trousers: Debating kastom, clothing and gender in the Vanuatu mediascape'. The Asia Pacific Journal of Anthropology 17(1): 17-33. doi.org/10.1080/14442213.2015.111 6595.

Cave, Danielle. 2012. Digital Islands: How the Pacific's ICT Revolution is Transforming the Region. Sydney: Lowy Institute for International Policy.

Christensen, Henrik Serup. 2011. 'Political activities on the Internet: Slactivism or political participation by other means?' First Monday 16. Online: firstmonday.org/ojs/index.php/fm/ article/view/3336 (accessed 13 August 2016). doi.org/10.5210/ fm.v16i2.3336.

Corbett, Jack and Asenti Liki. 2015. 'Intersecting identities, divergent views: Interpreting the experiences of women politicians in the Pacific Islands'. Politics and Gender 11(2): 320-44. doi.org/10.1017/ S1743923X15000057.

Cox, John. 2014. 'Fake money, Bougainville politics and international scammers'. State Society and Governance in Melanesia, in brief, 2014/7. Canberra: The Australian National University.

Dickson-Waiko, Anne. 2003. 'The missing rib: Mobilizing church women for change in Papua New Guinea'. Oceania 73(1-2): 98-119. doi. org/10.1002/j.1834-4461.2003.tb02838.x.

Donald, Isabelle, Jane Strachan and Hilda Taleo. 2002. 'Slo slo: Increasing women's representation in parliament in Vanuatu'. Development Bulletin 59: 54-57.

Douglas, Bronwen. 2002a, 'Christian citizens: Women and negotiations of modernity in Vanuatu'. The Contemporary Pacific 14(1): 1-38. doi. org/10.1353/cp.2002.0007.

__ 2002b. 'Why religion, race and gender matter in Pacific politics'. Development Bulletin 59: 11-14. 
Finau, Glen, Acklesh Prasad, Romitesh Kant, Jope Tarai, Sarah Logan, and John Cox. 2014. 'Social Media and e-Democracy in Fiji, Solomon Islands and Vanuatu'. In 20th Americas Conference on Information Systems. Georgia: Association for Information Systems (AIS).

George, Nicole. 2014. 'Promoting women, peace and security in the Pacific Islands: Hot conflict/slow violence'. Australian Journal of International Affairs 68(3): 314-32. doi.org/10.1080/10357718.2 014.902032 .

- 2012. Situating Women: Gender Politics and Circumstance in Fiji. Canberra: ANU E Press. Online: Online: press.anu.edu.au/ publications/situating-women (accessed 12 August 2016).

—. 2009. "'Situating" active citizenship: Historical and contemporary perspectives of women's organising in the Pacific'. Development in Practice 19(8): 981-96. doi.org/10.1080/09614520903220826.

Gerbaudo, Paul. 2012. Tweets and the Streets: Social Media and Contemporary Activism. London: Pluto Press.

Haley, Nicole and Kerry Zubrinich. 2015. 'Mobile phones and the 2014 Solomon Islands National Elections'. State Society and Governance in Melanesia, in brief, 2015/28. Canberra: The Australian National University.

International Women's Development Agency (IWDA). 2015. 'The Beijing Platform For Action: IWDA partner perspectives 20 years on'. Gender Matters 6. Online: www.iwda.org.au/resource/journalgender-matters-6/ (accessed 13 August 2016).

Kabeer, Naila. 2012. 'The power of association: Reflecting on women's collective action as a force for social change'. Thinkpiece \#2. London: UK Feminista.

- 2011. 'Between affiliation and autonomy: Navigating pathways of women's empowerment and gender justice in rural Bangladesh'. Development and Change 42(2): 499-528. doi.org/10.1111/j.14677660.2011.01703.x.

Kabeer, Naila and Lopita Huq. 2010. 'The power of relationships: Love and solidarity in a landless women's organisation in rural Bangladesh'. IDS Bulletin 41(2): 79-87. doi.org/10.1111/j.1759-5436.2010.00126.x. 
Kahn, Richard and Douglas Kellner. 2004. 'New media and internet activism: from the "Battle of Seattle" to blogging'. New Media and Society 6(1): 87-95. doi.org/10.1177/1461444804039908.

Lee, Helen. 2006. 'Debating Language and identity online: Tongans on the net'. In Native on the Net: Indigenous and Diasporic Peoples in the Virtual Age, ed. Kyla Landzelius, pp. 257-81. London and New York: Routledge.

Lipset, David. 2013, 'Mobail: Moral ambivalence and the domestication of mobile telephones in peri-urban Papua New Guinea'. Culture, Theory and Critique 54(3): 335-54. doi.org/10.1080/14735784.201 3.826501 .

Logan, Sarah. 2012. 'Rausim! Digital politics in Papua New Guinea'. State Society and Governance in Melanesia, discussion paper, 2012/9. Canberra: The Australian National University.

McDougall, Debra. 2003. 'Fellowship and citizenship as models of national community: United Church women's fellowship in Ranongga, Solomon Islands'. Oceania 74(1-2): 61-80. doi. org/10.1002/j.1834-4461.2003.tb02836.x.

McLeod, Abby. 2015. 'Women's leadership in the Pacific'. State of the Art Papers, no. 4, Birmingham: Developmental Leadership Program (DLP).

—_. 2002. 'Where are the women in Simbu politics'. Development Bulletin 59: 43-46.

Monson, Rebecca. 2013. 'Vernacularising political participation: Strategies of women peace-builders in Solomon Islands'. Intersections: Gender and Sexuality in Asia and the Pacific 33. Online: intersections. anu.edu.au/issue33/monson.htm (accessed 13 August 2016).

Nishitani, Makiko. 2014. 'Kinship, gender and communication technologies: Family dramas in the Tongan diaspora'. The Australian Journal of Anthropology 25(2): 207-22. doi.org/10.1111/taja.12089.

Pacific Institute of Public Policy (PiPP). 2012, Net Effects: Social and Economic Impacts of Telecommunications and Internet in Vanuatu. Port Vila: PiPP. 
Pacific Young Women's Leadership Alliance (PYWLA). 2013. Pacific Young Women's Leadership Alliance: Online Dialogue Issue Series. Suva: PYWLA.

Paina, Dalcy Tovosia. 2000. 'Peacemaking in Solomon Islands: The experience of the Guadalcanal Women for Peace movement'. Development Bulletin 53: 47-48.

Pollard, Alice Aruhe'eta. 2003. 'Women's organizations, voluntarism, and self-financing in Solomon Islands: A participant perspective'. Oceania 74(1-2): 44-60.

Riles, Annelise. 2001. The Network Inside Out. Ann Arbor, MI: University of Michigan Press.

Spark, Ceridwen. 2014. 'Developing Young women's collective action in Vanuatu'. State Society and Governance in Melanesia, in brief, 2014/28. Canberra: The Australian National University.

—. 2010. 'Changing lives: Understanding the barriers that confront educated women in Papua New Guinea'. Australian Feminist Studies 25(63): 17-30. doi.org/10.1080/08164640903499901.

Spark, C. and Corbett, J. 2016. 'Archetypes, Agency and Action: Emerging Women Leaders' Views on Political Participation in Melanesia'. International Feminist Journal of Politics. dx.doi.org/10.1080/146167 42.2016.1189680.

Surman, Tonya and Mark Surman. 2008. Listening to the Stars: The Constellation Model of Collaborative Social Change. Toronto: Canadian Partnership for Children's Health and the Environment (CPCHE).

Sutton, Jo and Scarlet Pollock. 2000. 'Online activism for women's rights'. CyberPsychology and Behaviour 3(5): 699-706. doi. org/10.1089/10949310050191700.

Taylor, John P. 2016. 'Drinking money and pulling women: Mobile phone talk, gender, and agency in Vanuatu'. Anthropological Forum 26(1): 1-16. doi.org/10.1080/00664677.2015.1071238.

World YWCA. 2011. Safe. Respect. Included. Connected. Skilled: A Pacific Young Women's Leadership Strategy (2011-2014). Geneva: World YWCA. 
This text is taken from Transformations of Gender in Melanesia, edited by Martha Macintyre and Ceridwen Spark, published 2017 by ANU Press, The Australian National University, Canberra, Australia. 